\title{
The Lipids of the Common House Cricket, Acheta domesticus L. I. Lipid Classes and Fatty Acid Distribution
}

RODERICK F. N. HUTCHINS ${ }^{1}$ and MICHAEL M. MARTIN, ${ }^{2}$ Department of Chemistry, University of Michigan, Ann Arbor, Michigan 48104

\section{ABSTRACT}

The lipids of the common house cricket, Acheta domesticus L., have been examined with the following results. The fatty acids associated with the lipid extracts do not change significantly from the third through the eleventh week of the crickets' postembryonic life. The major fatty acids are linoleic $(30-40 \%)$, oleic (23-27\%), palmitic (24-30\%), and stearic acids $(7-11 \%)$. There are smaller amounts of palmitoleic $(3-4 \%)$, myristic $(\approx 1 \%)$, and linolenic acids $(<1 \%)$. The fatty acid composition of the cricket lipids reflects but is not identical to the fatty acids of the dietary lipids: linoleic $(53 \%)$, oleic $(24 \%)$, palmitic $(15 \%)$, stearic $(3 \%)$, myristic $(2 \%)$, and linolenic acids $(2 \%)$.

The amount of triglycerides present in the crickets increases steadily from the second through the seventh or eighth week of postembryonic life, then drops sharply. Other lipid classes, such as hydrocarbons, simple esters, diglycerides, monoglycerides, sterols, and free fatty acids remain about constant. The composition of the fatty acids associated with the tri-, di-, and monoglycerides and the free fatty acid fraction are all about the same. The fatty acids associated with the simple esters are high in stearic acid.

\section{INTRODUCTION}

$I^{\mathrm{N} s e c t}$ NSECT LIPID metabolism is a topic of considerable current interest, and a number of good reviews covering the subject have appeared in the last five years (1-4). In this and the following two papers, the analysis and characterization of the lipids of the common house cricket, Acheta domesticus L., are reported. Because of the relative ease of maintaining laboratory colonies $(5,6)$ and because of the commercial availability in large quanti-

\footnotetext{
1 Postdoctoral Research Associate, Department of Chemistry, University of Michigan, 1965-1967.

${ }^{2}$ Associate Prof., Department of Chemistry, Universtty of Michigan; Alfred P. Sloan Foundation Fellow; to whom inquiries regarding this publication should be addressed,
}

ties of Acheta domesticus, this species is a particularly appealing one, both for biologically and chemically oriented studies. In this first paper the over-all lipid pattern in crickets at different stages of development is established, and the fatty acids associated with each lipid class are characterized. In the second and third papers the hydrocarbon and sterol fractions are examined in more detail.

\section{MATERIALS AND METHODS}

Live crickets were purchased from the Lucky Lure Cricket Hatchery, Whitmore Lake, Mich. The crickets were stored for $24 \mathrm{hr}$ without food and were separated from excretory products prior to being extracted.

\section{Lipid Extraction}

In a typical extraction $1,000 \mathrm{~g}$ (fresh weight) of crickets, immobilized by quick-freezing, were extracted in a 1-gallon Waring Blendor with two liters of ether-methanol $(3: 1)$. The marc was extracted twice with two-liter portions of ether-methanol $(3: 1)$. The three extracts were combined and separated into an ether and an aqueous phase. The ether phase was washed once with a saturated sodium chloride solution. To the aqueous phase was added an equal volume of saturated sodium chloride solution. It was then extracted with ether until the extracts were colorless. The combined ether extracts were dried in a preliminary fashion with sodium sulfate and concentrated on a rotary concentrator. The residue was dissolved in methylene chloride and dried over sodium sulfate. Filtration and concentration gave the crude lipid extracts studied in this and the next three papers.

\section{Lipid Separations}

Lipid separations were carried out by a modification of the method of Carroll (7). In a typical run, $5.0 \mathrm{~g}$ of lipid, dissolved in a minimum of petroleum ether (bp 40-60C, redistilled), was adsorbed on a column of $400 \mathrm{~g}$ of Florisil (Fisher), to which $20 \mathrm{~g}$ of water had previously been added. Hydrocarbons were eluted with petroleum ether, simple esters with ether-petroleum ether $(5: 95)$, triglycerides, and sterols, successively with ether-petroleum ether 
TABLE I

Fatty Acid Composition of Lipid Extracts of Acheta domesticus of Different Ages

\begin{tabular}{|c|c|c|c|c|c|c|c|c|c|}
\hline \multirow{2}{*}{$\begin{array}{l}\text { Postembryonic } \\
\text { age of crickets } \\
\text { (weeks) }\end{array}$} & \multicolumn{9}{|c|}{ Percentage Composition of Fatty Acids } \\
\hline & $<\mathrm{C}_{14}$ & $C_{14: 0}$ & $\mathrm{C}_{14: 1}$ & $\mathbf{C}_{16: 0}$ & $\mathrm{C}_{18: 1}$ & $C_{18: 0}$ & $C_{18: 1}$ & $C_{18: 2}$ & $\mathrm{C}_{18: 3}$ \\
\hline 3 & Trace & 1 & - & 25 & 4 & 11 & 27 & 30 & - \\
\hline 4 & Trace & 1 & 一 & 25 & 3 & 9 & 24 & 36 & - \\
\hline 5 & Trace & 1 & - & 24 & 2 & 8 & 26 & 37 & $<1$ \\
\hline 6 & Trace & 1 & - & 27 & 3 & 8 & 23 & 35 & 1 \\
\hline 8 & Trace & 1 & $<1$ & 26 & 2 & 8 & 23 & 40 & $<1$ \\
\hline $10^{1 / 2}$ & Trace & 1 & $<1$ & 30 & 2 & 7 & 24 & 39 & - \\
\hline Cricket food & Trace & 2 & $<1$ & 15 & 1 & 3 & 24 & 53 & 2 \\
\hline
\end{tabular}

(15:85), diglycerides with ether-petroleum ether (30:70), monoglycerides with methanolether (2:98), and free fatty acids with acetic acid-ether (4:96). Total amounts of each lipid class were determined gravimetrically. Duplicate runs gave results which were within 0.5 absolute per cent of each other.

\section{Free Fatty Acids}

These were converted into methyl esters for identification and quantitation determination by gas-liquid chromatography (GLC). Esterification was carried out using $14 \%$ boron trifluoride-methanol reagent (Applied Science Laboratories) by the method of Metcalf and Schmitz (8). Fatty acids in esterified lipids were converted into methyl esters for GLC analysis by transesterification using the same procedure as modified by Peterson et al. (9). GLC analyses were conducted on an F and M Model 810 dual-column chromatograph, equipped with a flame ionization detector. The column of choice was a 6 -ft $\times 1 / 8$-in. $6 \%$ diethyleneglycol succinate (LAC-728) on acid-washed silanized Chromosorb $\mathrm{W}$. The carrier gas flow rate was $30 \mathrm{cc} / \mathrm{min}$, the detector temperature was $275 \mathrm{C}$, the injection port was $260 \mathrm{C}$, and the column was maintained at a constant temperature between $150 \mathrm{C}$ and $175 \mathrm{C}$. Peak areas were determined either by triangulation or with the aid of a disc integrator. Duplicate analyses con- ducted on crude lipid extracts or lipid fractions gave percentage compositions for major components within two or three absolute per cent of one another and values for minor components within one absolute per cent of one another. Identification of the fatty acids was achieved through a comparison of the retention times of the methyl esters with those of authentic samples (Applied Science Laboratories).

\section{RESULTS AND DISCUSSION}

\section{Diet, Age and Fatty Acid Composition}

In Table I are tabulated the fatty acid compositions of the total lipid extracts of crickets of different ages. Also included for comparison is the fatty acid composition of the lipids of the cricket food. There appear to be no dramatic differences in the fatty acid composition of the lipid extracts derived from crickets of different ages. The comparatively lower value for linoleic acid in three-week-old crickets is probably real, but even there the change as the insect ages is extremely small. The fatty acid composition of cricket lipids is in no way remarkable and shows a pattern similar to those exhibited by two other Orthopterans, Melanoplus sanguinipes (10) and Gryllus bimaculatus (11).

The influence of dietary lipids is also apparent. The three major acids of the food are also

TABLE II

Composition by Class of Lipids from Acheta domesticus of Different Ages

\begin{tabular}{|c|c|c|c|c|c|c|c|c|c|}
\hline \multirow{2}{*}{$\begin{array}{l}\text { Postembryonic } \\
\text { age of crickets } \\
\text { (weeks) }\end{array}$} & \multicolumn{9}{|c|}{ Lipid Class (mg of Fraction/g Fresh Weight) } \\
\hline & Total & $\begin{array}{l}\text { Hydro- } \\
\text { carbons }\end{array}$ & $\begin{array}{l}\text { Simple } \\
\text { esters }\end{array}$ & $\begin{array}{l}\text { Triglyc- } \\
\text { erides }\end{array}$ & Sterols & $\begin{array}{l}\text { Diglyc- } \\
\text { erides }\end{array}$ & $\begin{array}{l}\text { Monoglyc- } \\
\text { erides }\end{array}$ & $\begin{array}{l}\text { Fatty } \\
\text { acids }\end{array}$ & $\begin{array}{c}\text { Unre- } \\
\text { covered }\end{array}$ \\
\hline 2 & 48.4 & 2.4 & 0.4 & 21.3 & 2.6 & 2.5 & 3.3 & 2.2 & 11.9 \\
\hline 3 & 54.8 & 2.0 & 0.4 & 32.1 & 2.5 & 1.8 & 1.0 & 1.0 & 12.3 \\
\hline 4 & 60.1 & 1.9 & 0.5 & 40.3 & 3.1 & 2.1 & 0.8 & 0.8 & 9.2 \\
\hline 5 & 65.9 & 2.0 & 0.4 & 44.1 & 2.4 & 2.6 & 2.6 & 2.6 & 8.2 \\
\hline 6 & 77.1 & 2.3 & 1.2 & 53.2 & 1.9 & 3.8 & 1.5 & 1.5 & 10.3 \\
\hline 7 & 78.6 & 2.6 & 0.9 & 52.7 & 3.7 & 2.1 & 3.5 & 3.5 & 11.9 \\
\hline 8 & 76.9 & 3.7 & 1.5 & 49.9 & 2.7 & 2.9 & 1.4 & 1.4 & 15.0 \\
\hline $101 / 2$ & 49.4 & 2.1 & 0.6 & 29.1 & 2.5 & 2.2 & 1.3 & 1.3 & 9.1 \\
\hline Average & - & 2.4 & $\ldots$ & - & 2.7 & 2.5 & 2.2 & 1.8 & 11.0 \\
\hline
\end{tabular}

LiPIDS, VoL. 3, No. 3 
TABLE III

Composition of Fatty Acids Associated with Lipid Classes from Eight-Week-Old Acheta domesticus

\begin{tabular}{|c|c|c|c|c|c|c|c|c|c|}
\hline \multirow[b]{2}{*}{ Lipid class } & \multicolumn{9}{|c|}{ Percentage Composition of Fatty Acids } \\
\hline & $<C_{14}$ & $C_{14 ; 0}$ & $C_{14: 1}$ & $C_{10: 0}$ & $C_{16: 1}$ & $C_{18: 0}$ & $C_{18: 1}$ & $C_{18: 2}$ & $C_{18: 3}$ \\
\hline Simple esters & Trace & 1.0 & Trace & 20.5 & 3.0 & 19.0 & 21.5 & 34.0 & Trace \\
\hline Triglycerides & Trace & 1.0 & Trace & 22.5 & 3.0 & 7.0 & 27.5 & 37.0 & 2.0 \\
\hline Diglycerides & Trace & 0.5 & Trace & 25.0 & 3.0 & 6.0 & 26.0 & 39.0 & 1.5 \\
\hline Monoglycerides & Trace & 1.0 & Trace & 28.5 & 3.0 & 7.0 & 22.0 & 37.5 & 1.5 \\
\hline Free acids & Trace & 0.5 & - & 23.5 & 2.5 & 9.0 & 26.0 & 37.5 & 1.0 \\
\hline
\end{tabular}

the three major acids of the cricket. The cricket does seem to store the saturated acids, palmitic and stearic, and utilize the unsaturated acid, linoleic, preferentially since the cricket lipids are higher and lower respectively in these acids than is the cricket food. This is in accord with the data of House et al. (12), who demonstrated that dietary polyunsaturated lipids can increase the degree of unsaturation of depot fat only up to a certain level.

\section{Lipid Composition and Age}

In Table II the breakdown of the lipids into classes, that is, hydrocarbons, simple esters, triglycerides, sterols, diglycerides, monoglycerides, and free fatty acids for crickets of varying ages is presented. From the first column of Table II, it is clear that there is a build-up of depot fat during the first seven or eight weeks of the crickets' postembryonic life. This is followed by a loss of lipid between the eighth and eleventh week. From the fourth column it is apparent that it is the triglyceride fraction which is primarily responsible for the changes in total amounts of lipid which are present in the cricket. There also appears to be a small increase in the quantity of simple esters although the magnitude of the effect is on the borderline of experimental significance. The other lipid classes, hydrocarbons, sterols, diglycerides, monoglycerides, simple fatty acids, and highly polar unrecovered lipids appear to remain at fairly constant low levels throughout the crickets' life. The increase in triglyceride between the second and eighth week and the subsequent rapid decline between the eighth and eleventh week would seem most likely to be associated with the processes of egg development and oviposition.

\section{Fatty Acids Associated with Each Lipid Class}

In Table III are tabulated the compositions of the fatty acids associated with each lipid class isolated from 8 -week-old crickets. It would appear that the free fatty acid fraction and the fatty acids derived from the mono-, di-, and triglyceride fractions are similar. Only the simple ester fraction appears to be distinctive in that it contains an unmistakably higher proportion of stearic acid and also seems to differ from the other fractions in some of the minor components. It contains less linolenic acid and more $(1 \%)$ of an unknown material which has a retention close to that anticipated for a straight-chain 16-carbon doubly-unsaturated acid, a straight-chain 17-carbon acid, or a branched-chain 18-carbon acid.

\section{ACKNOWLEDGMENT}

The work was supported in part by the University of Michigan Cancer Research Institute and the American Cancer Society.

\section{REFERENCES}

1. Fast, P. G., Mem. Ent. Soc. Can. No. 37, 1-50 (1964)

2. Gilby, A. R., Ann. Rev. Ent. 10, 141-160 (1965).

3. Gilmour, D., "Biochemistry of Insects," Academic Press, New York, 1966, ch. VIII, pp. 203-234.

4. Gilmour, D., "The Metabolism of Insects," Oliver and Boyd, London, 1965, ch. IV, pp. 78-107.

5. Ghouri, A. S. K., and J. E. McFarlane, Can. Entomol. $90,158-165$ (1958).

6. McFarlane, J. E., Can. J. Zool. 42, 645-647 (1964)

7. Carroll, K. K., J. Lipid Res. 2, 135-141 (1961).

8. Metcalf, L. P., and A. A. Schmitz, Anal. Chem. 33 363-364 (1961).

9. Peterson, J. I., H. de Schmertzing and K. Abel, J. Gas Chromatog. 126-130 1965.

10. Barlow, J. S., Can. J. Biochem. 42, 1365-1374 (1964).

11. Fast, P. G., Ibid. 45, 503-505 (1967).

12. House, H. L., D. F. Riorden and J. S. Barlow, Can. J. Zool. 36, 629-632 (1958).

[Received July 17, 1967] 